\title{
Motor Evoked Potentials and Disability in Secondary Progressive Multiple Sclerosis
}

\author{
D. Facchetti, R. Mai, A. Micheli, N. Marcianó, R. Capra, \\ R. Gasparotti and M. Poloni
}

\begin{abstract}
Background: To investigate the mechanisms underlying disability in multiple sclerosis (MS), 40 patients with the relapsing-remitting form of the disease and 13 patients with secondary progressive MS underwent multimodal evoked potential (EP), motor evoked potential (MEP), and spinal motor conduction time evaluation. Clinical disability was evaluated by the expanded disability status scale (EDSS) and functional system scales. In secondary progressive MS patients, magnetic resonance imaging (MRI) was used to obtain a semiquantitative estimate of the total lesion load of the brain. Results: Spinal motor conduction time was significantly longer in secondary progressive MS patients than controls $(p<0.001)$ and relapsing-remitting MS patients $(p<0.05)$, but did not differ between relapsing-remitting patients and controls. Spinal motor conduction times also correlated directly with EDSS scores ( $p<$ $0.001)$ and pyramidal functional system scores $(\mathrm{p}<0.001)$. Brain lesion load $\left(4960.3 \pm 3719.0 \mathrm{~mm}^{2}\right)$ and the total number of lesions $(67.7$ $\pm 37.0)$ in secondary progressive MS did not correlate with disability scores. For the following EPs, the frequencies of abnormalities were significantly higher in secondary progressive MS patients than relapsing-remitting patients: visual evoked potentials ( $p<0.05$ ), somatosensory evoked potentials and upper limb motor evoked potentials $(p<0.01)$, and brainstem auditory evoked potentials, lower limb somatosensory evoked potentials and lower limb motor evoked potentials $(p<0.001)$. Conclusions: These findings suggest that disability in secondary progressive MS patients is mainly due to progressive involvement of corticospinal tract in the spinal cord.
\end{abstract}

RÉSUMÉ: Potentiels évoqués moteurs et invalidité dans la sclérose en plaques secondaire progressive. Introduction: Nous avons investigué les mécanismes sous-jacents à l'invalidité dans la sclérose en plaques (SEP) au moyen des potentiels évoqués multimodaux (PE), des potentiels évoqués moteurs (PEM) et du temps de conduction moteur spinal chez 40 patients atteints de la forme récurrente-rémittente et de 13 patients atteints de SEP secondaire progressive. L'invalidité clinique a été évaluée au moyen de l'échelle d'invalidité élargie (EIE) et d'échelles des systèmes fonctionnels. Dans la SEP secondaire progressive, l'imagerie par résonance magnétique (RMN) a été utilisée pour estimer semiquantitativement la charge lésionnelle totale du cerveau. Résultats: Le temps de conduction moteur spinal était significativement plus long chez les patients atteints de SEP secondaire progressive que chez les contrôles $(\mathrm{p}<0.001)$ et les patients atteints de la forme récurrente-rémittente $(\mathrm{p}<0.05)$, mais était semblable chez les patients atteints de la forme récurrente-rémittente et les contrôles. Les temps de conduction moteurs spinaux étaient directement corrélés avec les scores EIE (p $<0.001)$ et les scores du système pyramidal $(\mathrm{p}<0.001)$. La charge lésionnelle du cerveau $\left(4960.3 \pm 3719.0 \mathrm{~mm}^{2}\right)$ et le nombre total de lésions $(67.7 \pm$ 37.0) dans la SEP secondaire progressive n'étaient pas corrélés avec les scores d'invalidité. La fréquence des anomalies était significativement plus élevée chez les patients avec une SEP secondaire progressive que chez les patients atteints de la forme récurrente-rémittente pour les PEs suivants: les potentiels évoqués visuels $(\mathrm{p}<0.05)$, les potentiels évoqués somesthésiques et les potentiels évoqués moteurs des membres supérieurs $(\mathrm{p}<0.01)$, les potentiels évoqués auditifs du tronc cérébral, les potentiels évoqués somesthésiques des membres inférieurs et les potentiels évoqués moteurs des membres inférieurs $(\mathrm{p}<0.001)$. Conclusions: Ces observations suggèrent que l'invalidité est due principalement à une atteinte progressive des voies corticospinales de la moelle épinière chez les patients présentant la forme secondaire progressive de la SEP.

Can. J. Neurol. Sci. 1997; 24: 332-337

In most cases multiple sclerosis (MS) has a relapsing-remitting course but in a consistent number of patients the disease eventually becomes progressive. Although demyelination involves different neurological systems, disability in MS is mainly due to impairment of motor performance.

The study of the motor potentials evoked by magnetic stimulation is a recently introduced, painless and reliable technique for assessing motor pathways..$^{1-4}$ Comparison of upper and lower limb motor evoked potentials (MEPs) provides information about motor conduction along the corticospinal tract in brain and spinal cord. In assessing damage to the corticospinal tract
MEPs seem able to give much more useful information than magnetic resonance imaging (MRI), since although imaging abnormalities are frequently found in the brain and sometimes the cervical cord, these usually correlate poorly with clinical

From the Neurophysiology Service, Salvatore Maugeri Foundation, IRCCS, Gussago (Bs); Neurologic Clinic (N.M., R.C.) and Section of Neuroradiology (R.G.), Dept. of Radiology, University of Brescia, (Bs); III Neurologic Clinic (M.P.), University of Milan, San Paolo Hospital, Milan, Italy.

RECEIVED NOVEMBER 28, 1996. ACCEPTED IN FINAL FORM JUNE 16, 1997 Reprint requests to: Dante Facchetti, Servizio di Neurofisiologia, Centro Medico di Gussago, via Pinidolo 23, 25064 Gussago (BS), Italy 
signs and disability. ${ }^{5-10}$ Furthermore demyelination of the thoracic and lumbar spinal cord remains difficult to visualize on MRI. ${ }^{6.89}$

In this study we compared motor conduction abnormalities in relapsing-remitting MS with those found in secondary progressive MS. Our primary aim was to investigate the neurophysiological mechanisms underlying the progression of disability in the disease. Secondary aims were to evaluate the relationship between MEPs, clinical disability and the total lesion area of the brain in secondary progressive MS.

\section{METHODS}

\section{Patients and Settings}

Fifty-three patients with MS presenting at the MS Unit, Neurologic Clinic, University of Brescia over a 17 month period were selected for the present study. Forty had relapsing-remitting MS and 13, classified as secondary progressive MS, had an initially relapsing-remitting course that developed progressive deterioration over at least the preceding 12 months. All had clinically definite or laboratory supported MS, diagnosed according to the Poser criteria. " Patients with primary-progressive, probable or possible MS were excluded.

The patients underwent complete neurological examination, routine blood tests, cerebrospinal fluid examination, a preliminary MRI study and disability assessment. Additionally, the total lesion load of the brain demyelination was estimated by a semiquantitative MRI technique in the secondary progressive MS patients.

Neurophysiological examinations were performed at the Rehabilitation Center of Gussago (in the same week as the MRI study and disability assessment) by two of the authors who were blinded to the clinical, laboratory and MRI data. The neurophysiological data were compared to laboratory standard values obtained from 20 healthy subjects $(10$ men and 10 women; mean age $30.1 \pm 5.5 \mathrm{yr}$.) recruited from the Center's staff. Patients and controls gave informed consent to take part in the study, which was approved by the hospital ethics committee.

\section{Motor Evoked Potentials (MEPs)}

Motor potentials in upper and lower limbs were evoked by transcranial magnetic stimulation of motor cortical areas with a MES-10 Cadwell, 2.5 Tesla unit. The active electrodes were placed on the abductor digiti minimi and anterior tibial muscles bilaterally; four responses were superimposed to measure the latency. The peripheral responses were obtained by direct stimulation of the roots at C7 and L5 with the subject at rest. Output was set $30 \%$ higher than threshold. For cortical stimulation the digiti minimi were slightly abducted and the foot dorsiflected.

The central motor conduction time (CMCT) was defined as the difference between the latencies of the central and peripheral responses (cortex minus C7 or L5). Abnormal MEPs were defined as CMCTs at least 2.5 standard deviations greater than mean of the control group.

\section{Spinal Motor Conduction Time}

To assess conduction in the spinal section of the corticospinal tract we estimated the spinal motor conduction time ${ }^{12}$ by calculating the transit time between $\mathrm{C} 7$ and L5, as lower limb CMCT minus upper limb CMCT. Our findings in controls were consistent with expected spinal motor conduction times. ${ }^{12-15}$

\section{Multimodal Evoked Potentials (EPs)}

Patients and controls also underwent visual evoked potential (VEP), brainstem auditory evoked potential (BAEP), and somatosensory evoked potential (SEP) studies. In the latter, upper and lower limb studies were performed, stimulating the median and tibial nerves respectively. All these studies were performed in a semi-darkened room with patients in the seated (VEPs and BAEPs) or supine position (SEPs) using a Nicolet Pathfinder I Electrodiagnostic System, and surface electrodes applied with adhesive paste.

VEPs were recorded from $\mathrm{OZ}$ with $\mathrm{FZ}$ reference (10/20 international system). Two recordings, each an average of 100 responses, were made from each eye. Patients were instructed to fixate the central point of a checkerboard pattern which was reversed at a frequency of $1.6 \mathrm{~Hz}$. Filters were $1-100 \mathrm{~Hz}$, check size was 35 minutes of arc. The P100 latency and interocular latency difference were considered abnormal if differing from the mean of the control group by 2.5 standard deviations or more. Monoaural BAEPs were recorded from ipsilateral mastoid electrodes referred to $\mathrm{CZ}$. Filters were $100-3000 \mathrm{~Hz}, 1500$ responses to alternating clicks of duration of $0.1 \mathrm{~ms}$ were averaged. Analysis time was $10 \mathrm{~ms}$, repetition rate was $11.1 \mathrm{~Hz}$ and intensity was $60 \mathrm{~dB}$ above threshold. At least two reproducible sets of responses were obtained from each side. The absence of a wave, or I-III, I-V or III-V interpeak latencies at least 2.5 standard deviations greater the mean were considered abnormal.

Upper limb SEPs were recorded from Erb's point, cervical spine (CVI-contralateral Erb) and contralateral parietal area (2 $\mathrm{cm}$ behind $\mathrm{C} 3 / \mathrm{C} 4$ ) with $\mathrm{FZ}$ reference. The median nerve was stimulated at the wrist (repetition rate $3.3 \mathrm{~Hz}$, duration of $0.1 \mathrm{~ms}$ and intensity slightly above the motor threshold). Analysis time was $60 \mathrm{~ms}$ and filters were $15-1500 \mathrm{~Hz}$. At least two sets of data, each the average of 500 responses, were obtained from each side. Latencies were measured to the peaks of N13 and $\mathrm{N} 20$. N20-N13 interpeak latencies more than 2.5 standard deviations above the mean of normal subjects, or absence of potentials, were regarded as abnormal.

Lower limb SEPs were recorded from LI with reference on contralateral iliac spine, and from $\mathrm{CZ}(2 \mathrm{~cm}$ behind $\mathrm{CZ})$ with $\mathrm{FZ}$ reference. The tibial nerve was stimulated at the ankle at $2.3 \mathrm{~Hz}$ duration $0.1 \mathrm{~ms}$ and intensity slightly above the motor threshold. Analysis time was $100 \mathrm{~ms}$ and filters were $15-1500 \mathrm{~Hz}$. At least two responses, each the average of 500 single potentials, were obtained from each side. Latencies were measured to the peak of $\mathrm{N} 20$ and P40. P40-N20 interpeak latencies more than 2.5 standard deviation above the mean of normal subjects or absence of potentials were regarded as abnormal.

\section{Magnetic Resonance Imaging}

$\mathrm{T} 1$ and $\mathrm{T} 2$ weighted contiguous $5 \mathrm{~mm}$ thick slices were obtained in the axial plane with a 1.5 Tesla superconducting unit (Siemens Magneton). Gadolinium enhancement was not used. The total area of demyelinating lesions was estimated by a semiquantitative computerized method on $\mathrm{T} 2$ axial slices in patients with secondary progressive MS. All measurements were performed by the same investigator. Lesions were identified on computer images, each lesion was outlined manually and the area was calculated automatically. The total lesion area and the lesion area of each hemisphere were obtained as the sums of the areas of individual lesions. The total number of lesions and the 
number of lesions in each hemisphere were also recorded. Each slice was compared to the previous and next contiguous image to avoid counting the same lesion twice.

\section{Neurological Disability Scores}

Patients were assessed with the Kurtzke's expanded disability status scale (EDSS) and functional systems scoring. ${ }^{16}$

\section{Statistical Analysis}

Age and disease duration in relapsing-remitting MS and secondary progressive MS were compared by Student's t-test. Differences in disability scores were evaluated by the non-parametric Mann-Whitney test. The frequencies of EP and MEP abnormalities were compared by Fisher's exact test (two tails) for $2 \times 2$ table. Central motor conduction time and spinal motor conduction time between the two groups were compared by Kruskal-Wallis one-way ANOVA. Correlations between spinal motor conduction time and disability scores and between MRI data, disability scores and MEPs were evaluated by Spearman's rank correlation coefficients.

\section{Results}

\section{Clinical Characteristics}

Table 1 shows the characteristics of the two groups of MS patients. The groups did not differ significantly in terms of age (although relapsing-remitting MS patients were slightly younger) sex distribution (with two-thirds female preponderance in both) or mean disease duration (although this was slightly longer in the secondary progressive MS patients).

Table 1: Clinical Characteristics of Relapsing-Remitting MS and Secondary Progressive MS Patients.

\begin{tabular}{|c|c|c|c|}
\hline & $\begin{array}{l}\text { Relapsing-Remitting } \\
\text { MS (mean } \pm \text { SD) }\end{array}$ & $\begin{array}{l}\text { Secondary-Progressive } \\
\text { MS (mean } \pm \text { SD) }\end{array}$ & p-value \\
\hline $\begin{array}{l}\text { Patients } \\
\end{array}$ & 40 & 13 & \\
\hline Sex & $30 \mathrm{~F} / 10 \mathrm{M}$ & $10 \mathrm{~F} / 3 \mathrm{M}$ & ns* \\
\hline Age (years) & $36.0 \pm 10.0$ & $40.0 \pm 7.4$ & $n s^{*}$ \\
\hline Duration (years) & $8.1 \pm 7.5$ & $11.8 \pm 5.8$ & $\mathrm{~ns}^{*}$ \\
\hline EDSS & $1.6 \pm 1.1$ & $5.1 \pm 1.3$ & $<0.001^{* *}$ \\
\hline Pyramidal score & $1.5 \pm 0.9$ & $3.0 \pm 0.8$ & $<0.001^{* *}$ \\
\hline
\end{tabular}

Statistics: *Student's t-test; ${ }^{* *}$ Mann-Whitney. EDSS: expanded disability status scale.

\section{Central Motor Conduction Time and Spinal Motor Conduction Time}

Table 2 shows mean values and standard deviations of lower and upper limb CMCTs, and spinal motor conduction time in controls, and both MS groups. Both upper and lower limb CMCTs were significantly longer in both patient groups. The mean slowing was significantly greater in secondary progressive MS than relapsing-remitting MS. Mean spinal motor conduction time in secondary progressive MS was significantly slower than in controls ( $p$ $<0.001)$ and relapsing-remitting MS patients $(p<0.05)$. Spinal motor conduction time in the relapsing-remitting MS group was longer than in controls, but the difference was not significant.

\section{MEP and Multimodal EP Abnormalities}

The incidences MEP and EP abnormalities are shown in Table 3. A significantly higher percentage of abnormalities was observed in the secondary progressive MS group compared to the relapsing-remitting MS group. In the relapsing-remitting MS group VEPs were most often altered, followed by lower limb MEPs. In secondary progressive MS patients, lower limb MEPs were abnormal bilaterally in all cases and upper limb MEPs were abnormal in at least one arm in all cases. Lower limb SEPs were more altered than VEPs. A distal-to-proximal severity gradient of SEP and MEP abnormalities was discerned in both groups, but was particularly evident in the patients with secondary progressive MS.

Table 3: Frequencies of Multimodal Evoked Potential and Motor Evoked Potential Abnormalities in Relapsing-Remitting MS (40 cases) and Secondary Progressive MS (13 cases).

\begin{tabular}{lccc}
\hline Modality & $\begin{array}{l}\text { Relapsing- } \\
\text { Remitting } \\
\text { pts (\%) }\end{array}$ & $\begin{array}{l}\text { Secondary- } \\
\text { Progressive } \\
\text { pts (\%) }\end{array}$ & p-value \\
\hline VEPs & $23(57.5 \%)$ & $11(84.6 \%)$ & $<0.05$ \\
bilateral & $7(17.5 \%)$ & $10(76.9 \%)$ & \\
BAEPs & $7(17.5 \%)$ & $8(61.5 \%)$ & $<0.001$ \\
bilateral & $3(7.5 \%)$ & $6(46.1 \%)$ & \\
SEPs upper limb & $7(17.5 \%)$ & $7(53.8 \%)$ & $<0.01$ \\
bilateral & $3(7.5 \%)$ & $5(38.5 \%)$ & \\
SEPs lower limb & $13(32.5 \%)$ & $12(92.3 \%)$ & $<0.001$ \\
bilateral & $11(27.5 \%)$ & $11(84.6 \%)$ & \\
MEPs upper limb & $12(30.0 \%)$ & $13(100 \%)$ & $<0.01$ \\
bilateral & $8(20.0 \%)$ & $11(84.6 \%)$ & \\
MEPs lower limb & $17(42.5 \%)$ & $13(100 \%)$ & $<0.001$ \\
bilateral & $12(30.0 \%)$ & $13(100 \%)$ & \\
\hline
\end{tabular}

Statistics: Fisher's exact test adjusted for $2 \times 2$ table. Values were considered abnormal when 2.5 SD from the mean of controls. Bilateral: when EPs were abnormal on both sides.

Table 2: Central Motor Conduction Time (CMCT) of Upper and Lower Limbs and Spinal Motor Conduction Time (SMCT) in Controls, RelapsingRemitting MS and Secondary Progressive MS Patients.

\begin{tabular}{lcll}
\hline & Controls & $\begin{array}{l}\text { Relapsing-Remitting } \\
\text { MS } \\
\text { mean } \pm \text { SD (msec) }\end{array}$ & $\begin{array}{l}\text { Secondary-Progressive } \\
\text { MS } \pm \text { SD (msec) } \\
\text { mean } \pm \text { SD }(\mathbf{m s e c})\end{array}$ \\
\hline Upper Limbs CMCT & $6.3 \pm 0.8$ & $8.6 \pm 3.3^{*}$ & $13.4 \pm 4.6^{\alpha \beta}$ \\
\hline Lower Limbs CMCT & $13.4 \pm 1.3$ & $19.3 \pm 8.1^{*}$ & $34.2 \pm 12.6^{\alpha \beta}$ \\
\hline SMCT & $7.1 \pm 1.3$ & $10.7 \pm 6.2 \mathrm{~ns}$ & $21.2 \pm 9.4^{\alpha \beta}$ \\
\hline
\end{tabular}

msec: milliseconds. Statistics: Kruskal-Wallis one way ANOVA. ns = not significant compared to controls; ${ }^{*} \mathrm{p}<0.05$ compared to controls; ${ }^{\alpha} \mathrm{p}<0.05$ compared to relapsing-remitting MS; $\left({ }^{\beta} \mathrm{p}<0.001\right.$ compared to controls. 

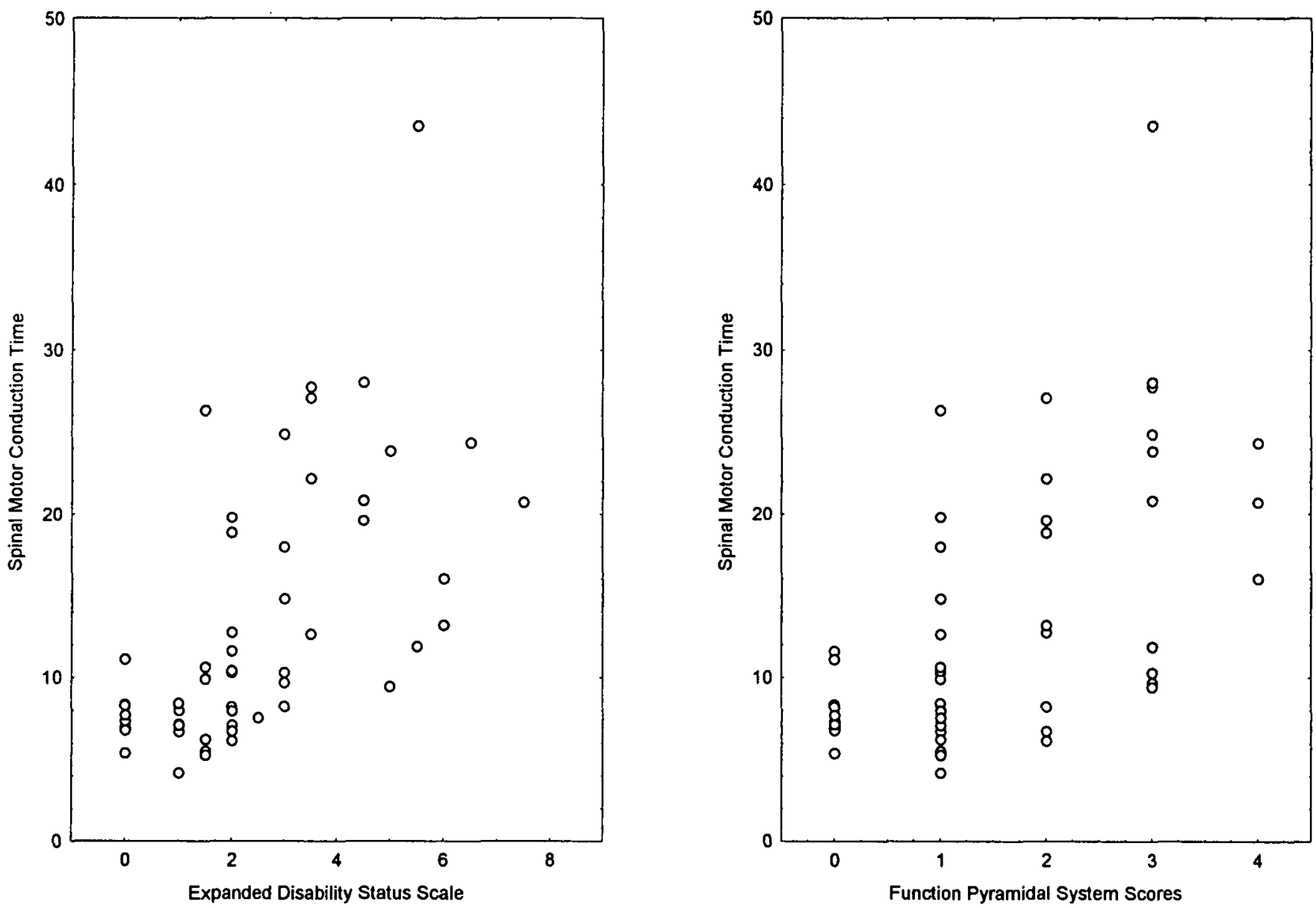

Figure 1: Scattered plot showing EDSS (A) and pyramidal functional system scores $(B)$ of the MS patients plotted against the spinal motor conduction time. Statistical analysis: Spearman's rank correlation coefficient: $A=0.69, P<0.001 ; B=0.60, p<0.001$.

\section{Disability Index}

EDSS and pyramidal functional system score were significantly worse in secondary progressive MS than in relapsing-remitting MS ( $p<0.001)$. A positive correlation was found between spinal motor conduction time and EDSS score $(p<0.001)$ and spinal motor conduction time and pyramidal system score $(p<0.001)$ (Figure 1).

\section{Magnetic Resonance Quantition of Lesion Load}

In the secondary progressive MS group, mean area of brain demyelination was $4,960.3 \pm 3,719.0 \mathrm{~mm}^{2}$ and the number of lesions was $67.7 \pm 37.0$ (with $2,562.2 \pm 1,731.3 \mathrm{~mm}^{2}$ involved and $35.1 \pm 21.4$ lesions in the right hemisphere and 2,398.1 \pm $2,097.2 \mathrm{~mm}^{2}$ involved and $32.6 \pm 17.3$ lesions in the left hemisphere). The combined area and number of lesions varied greatly from patient to patient (range 1,267-12,691 $\mathrm{mm}^{2}$, and 26-131 lesions respectively). No correlation was found between lesion area or number in one hemisphere and CMCT or spinal motor conduction time on the contralateral side. Furthermore there was no correlation between lesion area or number and EDSS or functional system scores, disease duration or age.

\section{Discussion}

In our study secondary progressive MS showed a worse clinical pattern and a significantly higher frequency of neurophysiological abnormalities than relapsing-remitting MS.

VEP, BAEP and SEP were more frequently abnormal bilaterally and, in the case of SEPs, were more frequently abnormal in lower limbs. These results are in agreement with those reported in the literature ${ }^{17-24}$ and do not require any further comment.

MEP alterations were frequent in our MS patients, more so in those with secondary progressive MS. The lower limbs were particularly affected, and bilateral lower limb involvement was present in all the secondary progressive patients. These findings paralleled the clinical condition of the patients, so that secondary progressive cases were more severely compromised and characterized by greater involvement of the lower than the upper limbs. MEPs are increasingly studied in demyelinating diseases $^{2.17-22.25-30}$ and relations between MEP abnormalities and MS clinical features such as weakness, plantar extensor response ${ }^{21,22,31,32}$ and, in longitudinal studies, changes in clinical status $^{27}$ have been established.

We found that conduction time in the cervico-lumbar tract was markedly increased in the secondary progressive group 
compared to both controls and the relapsing-remitting group, while was no significant difference in spinal conduction time between the relapsing-remitting MS group and controls. There was also a significant direct correlation between spinal motor conduction time and both EDSS score and pyramidal functional score, constituting further indication that MEPs are correlate closely with disability.

The measurement of spinal motor conduction time by MEPs is not without methodological bias. This applies to all non-invasive methods for determining spinal motor conduction which have limitations related to the uncertainty of position of the stimulation site (or recording site) in relation to the position of the electrical generator or site of excitation. ${ }^{12,13}$ An important limitation of the method used in this study derives from the fact that different fibers are involved in the corticocervical and corticolumbar pathways, and we recognize that the motor conduction times we measured are not true spinal motor conduction times. Furthermore cervical and lumbar conduction times may have sufficed to demonstrate greater involvement of lower limbs. Notwithstanding this we chose to determine the spinal motor conduction time in order to specifically investigate conduction in the axons running in the lower part of the spinal cord. We note finally the spinal conduction times we found in normal subjects were similar to those obtained by Eisen et al. ${ }^{12.13}$ and Snooks et al, ${ }^{14}$ and comparable to those obtained using direct spinal stimulation, ${ }^{15.23}$ confirming that the present methodology gave reasonably reliable results.

The reasons why many relapsing-remitting MS patients eventually develop a progressive course are not well understood. One pathophysiological mechanism responsible for this deterioration may be that of increasing extent of overall cerebral demyelination. We used a semiquantitative method to assess the total area of brain lesions on contiguous $5 \mathrm{~mm}$ thick MR images in the secondary progressive MS patients, and found that the total area of demyelination and the number of lesions varied widely between patients. However neither of these parameters correlated with EDSS or pyramidal functional scores. Central conduction time and spinal motor conduction time were also compared to total demyelination area, but again no correlation was found. Thus, in agreement with most authors ${ }^{7,10,33.34}$ our results seem to rule out total lesion burden in the brain as a major determinant of disability.

With regard to the relation between multimodal EPs and MRI findings, some publications report a significant direct correlation and others no correlation. ${ }^{35-37}$ This is probably because various criteria have been used to quantify MRI lesions, and also because of the heterogeneity of the MS populations studied.

Since it is well accepted that in MS there is an ongoing silent activity even when changes are not clinically appreciable, ${ }^{33,38-40}$ serial MRI studies are increasingly used to monitor disease activity and to assess outcomes in clinical trials. ${ }^{41,42}$ Recently a positive correlation has been shown between changes in disability and the rate of appearance of new demyelinating, enlarging or enhancing lesions in serial MRI. ${ }^{43-45}$ It is likely that the use of serial and gadolinium-enhanced MRI to assess changes in lesion volume, perhaps with the aid of techniques that can detect subtle changes in apparently normal white matter, ${ }^{46,47}$ will provide parameters that correlate more reliably with disability than the area measurement we used in the present study. We note, however, that most published studies report no correlation or feeble correlation between the extent of lesions on MRI and disability. ${ }^{7,10,33,34,38,48,49}$
The results of these studies and our own raise intriguing questions concerning the development of disability in MS. The fact that some patients develop disability apparently in the absence of new cerebral MRI lesions and without relation with the total lesion load in the brain indicates that more than one mechanism is involved in the development of disability in MS, among which may be progressive axonal loss in pre-existing lesions and involvement of the spinal cord.

Spinal cord neuroimaging remains an unsatisfactory method for assessing spinal cord involvement, and most previous studies of lesion load in MS did not even bother to image the spinal cord. Tartaglino et al. ${ }^{8}$ and Kidd et al. ${ }^{9}$ found that lesions often occurred in the cervical region and that the most common location for plaques were the dorsolateral areas of the cord. In a serial MRI study of brain and spinal cord with and without gadolinium, Kidd et al. ${ }^{50}$ found that clinical deterioration was independent of the appearance of new activity in the cord and suggested that the development of progressive disability might be related to mechanisms such as axonal loss not clearly demonstrable by MRI.

In general the lower limbs are more severely affected than upper limbs in MS. There is usually a progression towards paraparesis with spastic paralysis and clonus in the lower extremities whereas severe pyramidal impairment is seldom seen in the upper limb.

It is our opinion that demyelination or atrophy. of fast-conducting corticospinal axons could be responsible for slowing and dispersing the descending wave. This dispersion progressively increases with distance from the cortex, and this phenomenon would be more evident in fibers to the lower limbs because of their greater length. Furthermore the longer fibers might be intrinsically more susceptible to damage, as observed in peripheral nervous system conditions. Note also that less corticospinal fibers supply the lumbar enlargement than do the cervical tract, so that fewer or smaller lesions may cause more severe failure of the descending volley to lower limbs than to that of the upper limbs.

We note finally that involvement of the spinal section of the corticospinal tract may give rise to most disability in virtue of its strategic role in ambulatory function; this would be further exacerbated by the bias of the disability scales toward gait abnormalities and unbalance.

In conclusion, the results of this study indicate that secondary progressive MS patients are much more severely affected than relapsing remitting MS patients, that involvement of the spinal cord is important in determining this disability, and that MEPs are useful for monitoring it. This change is probably related to slowing and dispersion secondary to the involvement of the longer fast-conducting pyramidal fibers, that for most of their length run in the spinal cord.

\section{REFERENCES}

1. Barker AT, Jalinous R, Freeston IL. Non-invasive magnetic stimulation of human motor cortex. Lancet 1985; i: 1106-1107.

2. Hess CW, Mills KR, Murray NMF. Measurement of central motor conduction in multiple sclerosis by magnetic brain stimulation. Lancet 1986; 16:355-358.

3. Booth KR, Streletz LJ, Raab VE, et al. Motor evoked potentials and central motor conduction: studies of transcranial magnetic stimulation with recording from the leg. Electroencephalogr Clin Neurophysiol 1990; 81: 57-62. 
4. Murray NMF. The clinical usefulness of magnetic cortical stimulation. Electroencephalogr Clin Neurophysiol 1992; 85: 81-85.

5. Kidd D, Thompson AJ, Kendall BE, Miller DH, McDonald WI. Benign form of multiple sclerosis: MRI evidence for less frequent and less inflammatory disease activity. J Neurol Neurosurg Psychiatry 1994; 57: 1070-1072.

6. Wiebe S, Lee DH, Karlik SJ, et al. Serial cranial and spinal cord magnetic resonance imaging in multiple sclerosis. Ann Neurol 1992; 32: 643-646.

7. Thompson AJ, Miller D, Youl B, et al. Serial gadoliniumenhanced MRI in relapsing-remitting multiple sclerosis of varying disease duration. Neurology 1992; 42: 60-63.

8. Tartaglino LM, Friedman DP, Flanders AE, et al. Multiple sclerosis in the spinal cord: MR appearance and correlation with clinical parameter. Radiology 1995; 195: 725-732.

9. Kidd D, Thorpe JW, Thompson AJ, et al. Spinal cord MRI using multi-array coils and fast spin echo. II. Findings in multiple sclerosis. Neurology 1993; 43: 2632-2637.

10. Koopmans RA, Li DKB, Grochowski E, Curler PJ, Pary DW. Benign versus chronic progressive multiple sclerosis: magnetic resonance imaging features. Ann Neurol 1989; 25: 74-81.

11. Poser CM, Paty DW, Sheinberg L, et al. New diagnostic criteria for multiple sclerosis: guidelines for research protocols. Ann Neurol 1983,12: 227-231.

12. Eisen AA, Shtybel W. AAEM minimonograph \#35; clinical experience with transcranial magnetic stimulation. Muscle and Nerve 1990; 13: 995-1011

13. Eisen AA. Noninvasive measurement of spinal cord conduction: review of presently available methods. Muscle and Nerve 1986; 9: 95-103.

14. Snooks SJ, Swash M. Motor conduction velocity in the human spinal cord: slowed conduction in multiple sclerosis and radiation myelopathy. J Neurol Neurosurg Psychiatry 1985; 48: 1135-1139.

15. Fujiki $M$, Isono $M$, Hori $S$, Ueno $S$. Corticospinal direct response to transcranial magnetic stimulation in humans. Electroencephologr Clin Neurophysiol 1996; 10: 48-57.

16. Kutzke JF. Rating neurologic impairment in multiple sclerosis: an expanded disability status scale. Neurology 1983; 33: 1444 . 1452.

17. Ravnborg $M$, Liguori R, Christiansen $P$, Larsson H, SoelbergSørensen P. The diagnostic reliability of magnetically evoked motor potentials in multiple sclerosis. Neurology 1992; 42: 1296-1301.

18. Berardelli A, Inghilleri M, Cruccu G, et al. Stimulation of motor tracts in multiple sclerosis. J Neurol Neurosurg Psychiatry 1988; 51:677-683

19. Caramia MD, Bernardi G, Zarola F, Rossini PM. Neurophysiological evaluation of the central nervous impulse propagation in patients with sensorimotor disturbances. Electroencephalogr Clin Neurophysiol 1988; 70: 16-25.

20. Filippi M, Campi A, Mammi S, et al. Brain magnetic resonance imaging and multimodal evoked potentials in benign and secondary progressive multiple sclerosis. J Neurol Neurosurg Psychiatry 1995; 58: 31-37.

21. Hess CW, Mills KR, Murray NMF, Schriefer TN. Magnetic brain stimulation: central motor conduction studies in multiple sclerosis. Ann Neurol 1987; 22: 744-752.

22. Jones SM, Streletz LJ, Raab VE, Knobler RL, Lublin FD. Lower extremity motor evoked potentials in multiple sclerosis. Arch Neurol 1991; 48: 944-948.

23. Chiappa KH. Evoked Potentials in Clinical Medicine. Second edition. 1990. Raven Press. New York.

24. Khoshbin S, Hallett M. Multimodality evoked potentials and blink reflex in multiple sclerosis. Neurology $1981 ; 31: 138-144$

25. Mills KR, Murray NMF. Corticospinal tract conduction time in multiple sclerosis. Ann Neurol 1985; 18: 601-605.

26. Smith SJM, Claus D, Hess CW, et al. F responses and central motor conduction in multiple sclerosis. Electroencephalogr Clin Neurophysiol 1989; 74: 438-443.

27. Kandler RH, Jarrat JA, Davies-Jones GAB, et al. The role of magnetic stimulation as a quantifier of motor disability in patients with multiple sclerosis. J Neurol Sci 1991; 106: 31-34.

28. Berger AR, Shahani BT. Electrophysiologic evaluation of spinal cord motor conduction. Muscle Nerve 1989; 12: 976-980.
29. Beer S, Rosler KM, Hess CW. Diagnostic value of paraclinical tests in multiple sclerosis: relative sensitivities and specificities for reclassification according to the Poser committee criteria. J Neurol Neurosurg Psychiatry 1995; 59: 152-159.

30. Mayr N, Baumgartner C. Zeitlhofer J, Deecke L. The sensitivity of transcranial cortical magnetic stimulation in detecting pyramidal tract lesions in clinically definite multiple sclerosis. Neurology 1991; 41: 566-569.

31. Ingram DA, Thompson AJ, Swash M. Central motor conduction in multiple sclerosis: evaluation of abnormalities revealed by transcutaneous magnetic stimulation of the brain. J Neurol Neurosurg Psychiatry 1988; 51: 487-494.

32. Kandler RH, Jarrat JA, Gumpert EJW, et al. The role of magnetic stimulation in the diagnosis of multiple sclerosis. $J$ Neurol Sci 1991; 106: 25-30.

33. Smith ME, Stone LA, Albert PS, et al. Clinical worsening in multiple sclerosis is associated with increased frequency and area of gadopentetate dimeglumin-enhancing magnetic resonance imaging lesions. Ann Neurol 1993; 33: 480-489.

34. Miller DH, Barkhof F, Nauta JP. Gadolinium enhancement increases the sensitivity of MRI in detecting disease activity in multiple sclerosis. Brain 1993; 116: 1077-1079.

35. Baumhefner RW, Tourtellotte WW, Syndulko K, et al. Quantitative multiple sclerosis plaque assessment with magnetic resonance imaging. Its correlation with clinical parameters, evoked potentials and intra-blood-brain barrier IgG synthesis. Arch Neurol 1990; 47: 19-26.

36. Cutler JR, Aminoff MJ, Brant-Zavadazki M. Evaluation of patients with multiple sclerosis by evoked potentials and magnetic resonance imaging: a comparative study. Ann Neurol 1986; 20: 645-648.

37. Miller DH. Magnetic resonance in monitoring the treatment of multiple sclerosis. Ann Neurol 1994; 36: S91-S94.

38. Paty DW, Li DK, Oger JF, et al. Magnetic resonance imaging in the evaluation of clinical trials in multiple sclerosis. Ann Neurol 1994; 36: S95-S96.

39. Capra R, Marciano' N, Vignolo L, Chiesa A, Gasparotti R. Gadolinium-pentetic acid magnetic resonance imaging in patients with relapsing-remitting multiple sclerosis. Arch Neurol 1992; 49: 687-689.

40. Stone LA, Albert PS, Smith ME, et al. Changes in the amount of diseased white matter over time in patients with relapsing remitting multiple sclerosis. Neurology 1995; 45: 1808-1814.

41. The IFN $\beta$ multiple sclerosis study group. Interferon $\beta-1 b$ is effective in relapsing-remitting multiple sclerosis. I. Clinical results of a multicentre, randomized, double blind placebo controlled trial. Neurology 1993; 43: 655-661.

42. Paty DW, Oger JF, Kastruokoff LF, et al. MRI in the diagnosis of MS: a prospective study with comparison of clinical evaluation, evoked potentials, oligoclonal banding and CT. Neurology 1988; 38: 180-185.

43. McDonald WI, Miller DH, Thompson AJ. Are magnetic resonance findings predictive of clinical outcome in therapeutic trials in multiple sclerosis? The dilemma of interferon- $\beta$. Ann Neurol 1994; 36: 14-18.

44. Khoury SJ, Guttman CRG, Oraw EJ, et al. Longitudinal MRI in multiple sclerosis: correlation between disability and lesion burden. Neurology 1994; 44: 2120-2124.

45. Paty DW, Li DKB, the UBC MS/MRI study group and the INF $\beta$ multiple sclerosis study group. Interferon $\beta-1 b$ is effective in relapsing-remitting multiple sclerosis. II. MRI analysis results of a multicentre, randomized, double blind, placebo controlled, trial. Neurology 1993; 43: 662-667.

46. Grossman RI. Magnetization transfer in multiple sclerosis. Ann Neurol 1994; 36: S97-S99.

47. Filippi M, Capra R, Campi A, et al. Triple dose of gadoliniumDTPA and delayed MRI in patients with benign multiple sclerosis. J Neurol Neurosurg Psychiatry 1996; 60: 526-530.

48. Evans AC, Frank JA, Antel J, Miller DH. The role of MRI in clinical trials: comparison of image processing tecnique. Ann Neurol 1997; 41: 125-132.

49. IFN $\beta$ Multiple Sclerosis Study Group and the University of British Columbia MS/MRI Analysis Group. Interferon $\beta$ - $1 \mathrm{~b}$ in the treatment of multiple sclerosis: final outcome of the randomized contolled trial. Neurology $1995 ; 45: 1277-1285$.

50. Kidd D, Thorphe JW, Kendal BE, et al. MRI dynamics of spinal cord in progressive multiple sclerosis. J Neurol Neurosurg Psychiatry 1996; 60: 15-19. 